\title{
Re-opening Sudan: the Balance Between Maintaining Daily Living and Avoiding the Next Peak of COVID-19
}

\author{
Nada Fadul ${ }^{1}(1) \cdot$ Mohamed E. Hussein $^{2} \cdot$ Abdelaal A. Fadul $^{3}$ \\ Accepted: 11 March 2021 / Published online: 29 March 2021 \\ (C) The Author(s), under exclusive licence to Springer Nature Switzerland AG 2021
}

\begin{abstract}
Purpose of the Review To describe the intersectionality of healthcare and economy, and potential solutions to prevent the next peak of COVID-19 in Sudan.

Recent Findings Sudan has recently emerged from a 30-year dictatorship to face the COVID-19 pandemic in the midst of the worst economic crisis. Disease control measures that have been used in developed countries have been difficult to implement in Sudan due to economic, social, and structural challenges. There is a need for integration of data into the disease response plan and for community engagement to help with mitigation efforts. Youth-led community organizations were critical in the success of the Sudanese revolution. Their formal involvement in contact tracing and community awareness campaigns can be beneficial.

Summary The COVID-19 pandemic has brought to the surface many of the challenges facing the healthcare system in Sudan. Culturally tailored interventions are needed to prevent the next peak of COVID-19 in the country.
\end{abstract}

Keywords COVID-19 $\cdot$ Sudan healthcare $\cdot$ Pandemic response

\section{Introduction}

\section{The First Wave of the COVID-19 Pandemic in Sudan}

The COVID-19 pandemic reached a critical point during the first wave in Sudan with 13,875 cases as of end of September 2020 [1]. The increase in numbers necessitated a rapid move from the containment to the mitigation phase of the pandemic in early May. While there was a significant fluctuation in the daily number of new cases, the 7-day moving average continued to be around 70 cases by end of September 2020 indicating persistent disease activity in the country [2]. The highest burden of COVID-19 was in Khartoum, which is the most

This article is part of the Topical Collection on Tropical Disease in Conflict Regions

Nada Fadul

Nada.fadul@unmc.edu

1 Specialty Care Clinic, Division of Infectious Diseases, University of Nebraska Medical Center, 988106 Nebraska Medical Center, Omaha, NE 68198-8106, USA

2 School of Business, University of Connecticut, Storrs, CT, USA

3 Sudan Economic and Social Research Bureau, Khartoum, Sudan populated city in the country. However, by the end of the first wave, the disease activity increased in the northern state and other remote parts of the country [1]. There was likely an under-reporting of new cases due to the lack of widespread testing and delay in accessing healthcare for COVID-19. Modeling data predicted that the spread of the disease would continue with a reproductive factor (R0) of 2.5 and a doubling factor of 7 days, with total cases reaching 10,000 to 100,000 by mid-July $[3,4]$. Given the limitations in testing and access to care, the current numbers likely underestimate the true incidence of COVID-19 in Sudan.

The country lifted the stay-at-home measures on June 30 before seeing a steady decline in cases for 2 weeks or greater as recommended in other countries [5]. This decision was partly due to the significant economic sufferings imposed by the stay-at-home measures, which necessitated creating a balance between disease prevention and economic wellbeing. Many experts argue that while these stay-at-home measures have proven to be effective in industrialized countries, their devastating effect on the daily living of residents in lowincome countries might outweigh any benefit [6,7]. On the other hand, modeling data suggested that, without these measures, Sudan would have seen a greater and faster increase in cases during the first wave, which suggests that these measures played a role in preventing widespread disease in the 
country [4]. In this paper, we describe the factors influencing the level of COVID-19 in Sudan during the first wave. In addition, we propose strategies to mitigate those factors and help reduce the number of cases during the reopening phase, and the subsequent waves.

\section{The Current Status of Sudan's Economy and Healthcare}

Sudan was under a 30-year dictatorship that inflicted severe hardships on the population including a genocide in Darfur that resulted in over 300,000 deaths. After the success of the Sudanese revolution, which started in December 2018, Sudan is now under a transitional government composed of joint military and civilian rule. While the current government had made a significant effort to initiate healthcare reform, several barriers have arisen to slow down that process. Unfortunately, Sudanese emerged from their revolution, only to find themselves facing a global pandemic with little resources. One of the major challenges facing Sudan's effort to combat COVID19 is the economic crisis caused by high inflation rate and high level of poverty.

The economic conditions in Sudan worsened since 2011 when South Sudan split from Sudan and formed its own country taking with it most of the oil resources. It is estimated that nearly half of the population of Sudan lives under poverty and about $60 \%$ are unemployed or living on hourly low-wage jobs that can barely sustain their living expenses and do not offer health insurance benefits [8]. Most people rely on crowded public transportation to get to work [9]. Due to shortages of bread and cooking gas, standing in long lines became a daily routine for most people in the capital and other major cities. According to the Global Hunger Index, Sudan had an index of 32.8 in 2019, which is classified as alarming [10]. In addition, it is estimated that there are 3 million refugees, returnees, and internally displaced people currently in Sudan, the majority of whom reside in crowded camps with low access to healthcare and clean water [11].

Sudan's healthcare system was left completely de-funded by the previous regime with the majority of gross domestic product (GDP) spent on security forces [12]. While healthcare expenditure increased over the last decade, only $6.3 \%$ of the country's GDP was spent on healthcare as of 2017 [13,14]. A study of healthcare expenditure and outcomes has shown that healthcare expenditure was positively associated with life expectancy and negatively associated with neonatal, infant, and under five death [15]. A major move towards decentralization and privatization of the health system during the dictatorship made access to quality healthcare very difficult and created a barrier to any development efforts in the country [16,17]. Significant decreases in expenditure on the public health system by the dictatorship deprived poor people from access to health services because they could not afford the cost of private health services.
Furthermore, there are significant inequalities in the distribution of services in the country with most of tertiary healthcare facilities located in the capital and its surroundings making it inaccessible to those living in the rural areas.

Besides the lack of internal funding and support, Sudan's healthcare system has suffered the consequences of longstanding economic sanctions that lasted for 20 years and ended in 2017. The country remains on the US list of States Sponsors of Terrorism. This has prevented Sudan from accessing US federal development and research funding which has negatively affected its healthcare system as compared to the neighboring countries which have access to such funding [18].

While the country has witnessed a significant increase in the number of health profession schools over the past two decades, the shortage in medical personnel continues to be a major issue due to the fact that many healthcare professionals migrated from the country after graduation [19]. Moreover, the lack of coordination between academia and the health services has resulted in skill mix mismatch. Health workforce density is estimated to be around 4.1 physicians and 8.3 nurses and midwives per 10,000 population as of 2014 [20] with a geographic distribution that's mostly urban [21].

These factors combined led to poor health indicators in the country including shortages in essential medicine with only $43 \%$ of health facilities having access to these medications; lack of access to primary and antenatal care services with only $23 \%$ of deliveries taking place in a healthcare facility in 2018; high rates of maternal and infant mortality of 311 per 100,000 livebirths and 52 per 1000 livebirths, respectively [1]; and low rate of vaccination with approximately $60 \%$ coverage of DTP3 vaccine across Sudan [11].

The COVD-19 pandemic has brought to the surface many of the limitations of healthcare infrastructure in the country and led to a rapid spread of the disease as well as increased mortality which has reached $6.4 \%$. There have been anecdotal reports of increased mortality in the community due to nonCOVID-related conditions as well as undiagnosed respiratory illnesses. Several healthcare facilities closed their doors due to lack of protective equipment and healthcare personnel or the mere fear of encountering COVID-19 patients. Doctors started revolting against the system and left their post protesting the lack of personal protective equipment (PPE) and hazardous work conditions that they encountered [22]. Many young doctors reside in dense households with elderly parents and extended family members, so the fear of transmitting the disease to their families was another factor. This led to severe limitations in accessing healthcare for patients with chronic comorbid conditions such as those who are on hemodialysis. Reports of patients driving from one hospital to another seeking treatment for urgent and emergent conditions became common during the early days of the pandemic. Physicians have tried to fill some of the gap by volunteering at the isolation centers as well as providing telehealth services through 
social media apps such as WhatsApp. The situation improved with more public health facilities opening their doors, yet there remains a shortage and difficulty in accessing routine primary care.

\section{The Argument for Re-opening}

Anecdotal reports suggest that the stay-at-home measures have not been enforced in the capital and many other parts of the country, which raises a question about their effectiveness in countries like Sudan. Photographs and videos on social media from major markets and streets show large numbers of people aggregating around street vendors without practicing social distancing or using facemasks. Sudan has a median population age of 19 years [23], which is far lower than most industrialized countries, making it less likely to suffer from high mortality due to COVID-19. Therefore, morbidity and mortality from malnutrition and poverty due to the economic hardships imposed by lockdown may outweigh the risk of morbidity and mortality from COVID-19.

In addition to the poverty that forces many people to earn their living by working daily in the crowded markets, there are other reasons for the resistance to sheltering, social distancing, and wearing masks including political, social, religious, and old inherited beliefs. Politically, the supporters of the overthrown regime are mounting a campaign against the transitional government using their vast financial resources and control of many of the mosques. The mosques' imams use the prayer sessions to sow doubts of the existence of the disease. They claim that the transitional government is using it as an excuse to keep people home and stop them from protesting the high prices and shortages of bread and other daily necessities. One day after the lock-down ended on June 29, 2020, the country witnessed mass demonstrations on June 30 with thousands of people on the streets without wearing masks or practicing social distancing. The imams were also helped by some of the religious beliefs that nothing will happen to a believer unless it is God's will. Hence, wearing a mask or sheltering at home will not help if it is God's will that you be afflicted. On the other hand, you can mingle with crowds in the markets without getting infected, if that is God's will. There are also claims of native medicinal herbs inherited from ancient times that rural people believe will prevent and cure them from COVID-19. Such beliefs were widely spread through social media.

\section{Lessons Learned from the COVID-19 First Wave Response in Sudan}

Several challenges arose during the country's response to the first CVOID-19 wave, which created an opportunity for interventions before the beginning of a second wave. The first challenge was related to contact tracing for returning travelers. While Sudan closed its borders early on as a response to the pandemic, this did not prevent the spread of disease in the country. Many returning travelers refused to stay at the quarantine centers due to claims of lack of proper accommodations and food. Some returnees departed soon after their arrival in Khartoum to other cities without disclosing their destination or contact information. The circumstances around handling of returnees spread via social media along myths about the disease, which then exacerbated the fear, stigma, and government mistrust in the community. In an effort to improve transparency and establish trust, the federal ministry of health $(\mathrm{FMoH})$ provided daily updates on TV and radio, which helped in delivering accurate and up-to-date disease statistics. However, conflicting information from other governmental and non-governmental agencies led to confusion and criticism. Another challenge has been the lack of access to urgent and emergent healthcare for non-COVID-19-related conditions due to the shortage of facilities and medical personnel.

In spite of all these problems, the situation in Sudan is not hopeless. One of the promising aspects of the COVID-19 response is the involvement of community, especially youth groups. During the Sudanese revolution, several youth-led organizations emerged and organized demonstrations as well as community support interventions. These organizations are commonly referred to as resistance committees and neighborhood committees. After the revolution, many committees directed their work towards rebuilding and rehabilitating the local neighborhoods. Many localities depend on these youth groups to assist with COVID-19 contact tracing and enforcement of public health measures. While they continue to play an important role in pandemic control, their efforts have not been formally structured or monitored for effectiveness, reach, or implementation. In the next section, we discuss the role of the youth as part of strategies to prevent a future peak of the pandemic.

\section{Response to COVID-19 During the Second Wave}

Sudan saw a steady increase in new cases of COVID-19 starting in November 2020. The second wave of the pandemic has been even harder to control due to the lack of funding to continue the operation of public health services such as contact tracing and home management programs. In addition, several societal factors related to COVID-19 are fatigue, stigma, and in some instances, denial of the existence of the disease. The June 30th demonstrations which immediately followed the lockdown exacerbated the conspiracy theories around COVID-19 as the predicted peak did not occur after the demonstrations. While the absence of the peak can be 
explained by several factors including the fact that these demonstrations occurred in outdoor environments which are known to lead to lower rates of spread, it created fertile ground for claims that the transitional government is using COVID19 as an excuse to suppress the youth from expressing their dissatisfaction with its performance. As of mid-February 2021, Sudan has a cumulative case number that exceeded 28,000 confirmed cases and over 1800 deaths due to COVID-19 [1]. The country experienced a massive shortage of healthcare personnel, facilities, and oxygen shortage. Many non-governmental entities and diaspora organizations mobilized resources to assist the $\mathrm{FMoH}$ in their response to COVID-19 during the second wave. This included fundraising for oxygen tankers and cylinders for major isolation centers as well as providing financial and logistic support to healthcare personnel to continue to operate these centers. Sudan is a member of Gavi vaccine alliance which is coleading COVAX, the COVID-19 vaccine arm of the World Health Organizations Access to COVID-19 Tools (ACT) Accelerator. It is expected that Sudan will receive free vaccine for $20 \%$ of its population from Gavi. However, due to the lack of funding to purchase massive number of doses beyond what is being provided by COVAX, it is expected that vaccination rate will not be able to keep up with the rapid spread in the community, and therefore, efforts will need to be directed to strengthening prevention strategies alongside vaccine rollout.

\section{Suggested Strategies for Preventing Future Peaks}

As an alternative to imposing stay-at-home and lockdown measures, the government should invest in aiding citizens on how to perform their daily lives in a safer way. This will help citizens strike a balance of going back to work and sustaining their livelihood while preventing widespread transmission of disease. All these factors can be addressed by the right policy and actions. First, the government, especially the medical professionals, must win the propaganda war by designing the right educational materials and enlisting the many enlightened religious leaders to participate in the campaign. Second, implement the planned government cash subsidies to lowincome families and encourage high-risk family members to shelter and follow all the procedures. Third, enlist the youthrun organizations and committees to help promote prevention activities in structured and sustainable way. Many youth committees already stand on the bread's and other necessities' line to buy them for high-risk people in their neighborhoods.

COVID-19 is not only a health problem but also a political and social problem even in developed countries. As have been documented in some states in the USA where lack of clear policies requiring mask wearing, sheltering and social distance requirements led to increased cases and subsequent enforcement of stricter social distancing and sheltering requirements [24]. At the same time, clear strategies are successful even in developing countries. The International Monetary Fund (IMF) reported that Vietnam has succeeded in containing the pandemic as there were only 352 confirmed cases [25]. The Vietnamese strategy was deployed quickly with the help of grass-root organizations and the military and security organizations. More importantly effective and transparent communications won the population buy-in. These actions helped eradicate the pandemic in Vietnam and can be adopted in Sudan.

With the country re-opening its doors before a clear decline in cases, there is a concern that the peak will be higher than anticipated unless innovative measures are taken to prevent community transmission. In order for the country's leadership to navigate these difficult circumstances, a careful consideration has to be given to (1) leveraging data to inform policy and interventions; (2) involving the community in decisionmaking and implementation; and (3) implementing evidencebased measure in a culturally responsive way. The interplay of these measures is illustrated in Fig. 1.

1. Leveraging data to inform policy and interventions: One of the biggest challenges facing Sudan in its effort to combat COVID-19 is the poor public health infrastructure and surveillance systems for disease tracking and containment. This hinders the country's ability to conduct systematic outbreak investigations to identify focal points. Integrated disease surveillance systems are critical for several aspects of communicable disease control such as identifying and studying disease risk factors, evaluating prevention and control efforts, and targeting public health resources. These surveillance systems help not only to track disease activity in the country but also to develop locally applicable interventions. Furthermore, the output

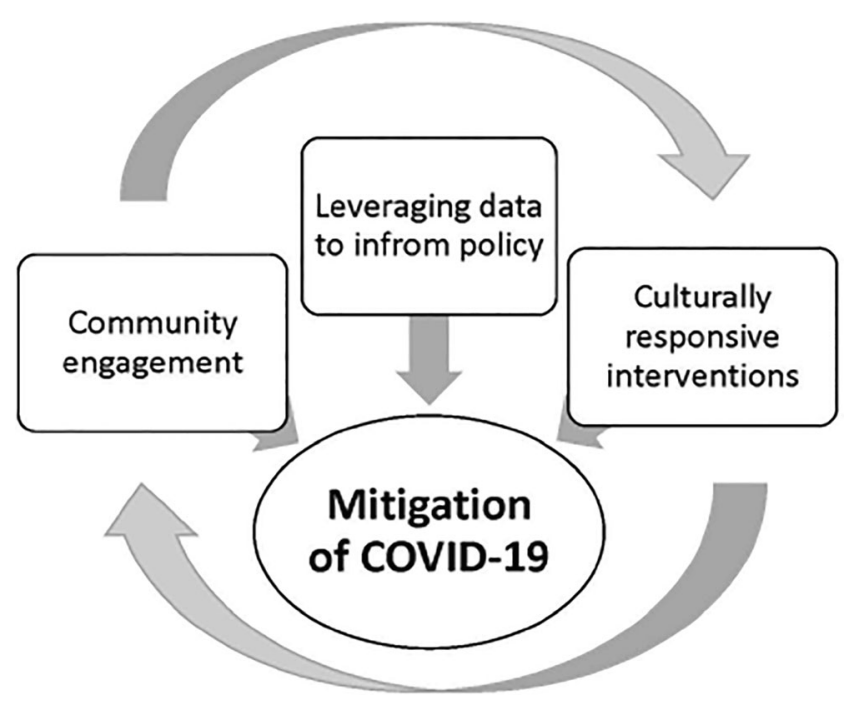

Fig. 1 Core elements of COVID-19 prevention strategy in Sudan 
of these systems can be utilized to increase awareness about the disease and its activity in local communities. Traditionally, surveillance systems have been developed and upgraded as a response to disease outbreaks in certain parts of the country. However, sustainable and continuous upgrade of these systems remains a challenge [26,27].

In 2015, the University of Oslo with the support of the Global Fund provided technical assistance to the Sudan FMoH to implement the District Health Information System 2 (DHIS2), which is an open-source, web-based health management information system and is the world's largest platform in use by 72 low-income and middleincome countries and is endorsed by the World Health Organization [28]. Sudan has moved from the pilot phase to the national phase of implementation of the system as it is currently in use in the State of Khartoum. In March, FMoH started setting up a new module DHIS2-COVID19 to accelerate case detection, situation reporting, and active surveillance and response for COVID-19. In general, the system is functional, but there are significant user adoption challenges reported locally.

It is prudent that the country invests in massive public health surveillance infrastructure that links laboratory testing, community health centers, state, and federal ministries of health with case management, contact tracing efforts, and other COVID-19 response efforts. Such a link can help in the early identification of community outbreaks and preventing further disease spread. Surveillance systems can also help investigate where disease disparity exists in the country so that targeted interventions to promote health equity and access can be implemented. In addition to the national disease surveillance system, there are several local efforts within the various governmental agencies as well as community and professional organizations to build COVID-19 tracking systems. Coordination of these efforts is crucial to prevent duplication and errors.

2. Involving the community in decision-making and implementation: Community engagement was found to be an effective method of contact tracing during the Ebola outbreak in West Africa [29,30]. Community engagement can be helpful in dispelling the myths and decreasing the stigma associated with the disease which were fueled by misinformation and skepticism about the existence of the disease among the lay public [31]. Community leaders such as local religious figures and tribal leaders can play an integral role in establishing trust between the public and authorities, especially in places where mistrust has developed due to the long-standing history of government oppression, brutality, and corruption. In addition to community leaders, social media influencers can play an important role in bridging the communication gap between the authorities and the public. Many of these influencers were active in supporting the Sudanese revolution which gained them respect and trust in the community. For their role to be effective, it is crucial to train community leaders and influencers on disease transmission and prevention methods. Transparency and support from government authorities are needed in order to make these efforts effective.

Attention should be given to structuring and monitoring the efforts of resistance committees and neighborhood committees in COVID-19 prevention and contact tracing. Mapping of these activities can help the government identify areas where there are gaps in community involvement which can then help in directing resources to areas in need. Formal training of these groups in public health interventions and strategies can help.

Considerations for community involvement should also incorporate efforts to engage the Sudanese diaspora. During the previous regime, large numbers of Sudanese immigrated to the Gulf and other industrialized countries to seek better employment opportunities and child education or to flee the oppression and atrocities committed by the previous regime against its political opponents. Sudanese diaspora played a major role in supporting Sudan during the revolution by raising international community's awareness about the human rights violations committed against demonstrators in Sudan. The diaspora provided significant financial contributions to aid in the organization of the demonstrations as well as treatment of those who were injured. Their efforts continued during the COVID-19 pandemic by providing financial aid to health institutions to purchase PPE, fundraising for oxygen supply, and organizing social media awareness campaigns. In addition, diaspora organizations played a major role in mobilizing the community to assist in COVID-19 response at the neighborhood level by training medical and non-medical personnel on the basics of community prevention and home isolation. These promising efforts can provide the foundation for community response and should be scaled up and expanded to all regions in the country.

Sudanese physicians in the diaspora played a significant role in guiding these efforts as well as providing training, capacity building, technical support, and transfer of knowledge [19,32].

3. Implementing evidence-based measure in a culturally responsive way

Table 1 highlights some of the necessary steps that need to be taken considering the challenges facing the healthcare system and the difficulties in implementing social distancing in Sudan. This model is based on the US "Box-It-In" strategy [33] with some modifications to fit the current environment and limited resources in Sudan. When 
Table 1 Bundle for COVID-19 prevention during re-opening phases

\begin{tabular}{|c|c|c|c|}
\hline Intervention & Current evidence & Challenges in Sudan & Strategies for Implementation \\
\hline Facemasks & $\begin{array}{l}\text { - Face masks, including simple cloth masks, reduce } \\
\text { transmission of COVID-19 by preventing the } \\
\text { spread of respiratory droplets from infected } \\
\text { persons to their surroundings. }\end{array}$ & $\begin{array}{l}\text { - Poor adherence } \\
\text { - Common misconception that only } \\
\text { surgical masks are effective in } \\
\text { preventing transmission } \\
\text { - Use of surgical masks in the } \\
\text { community may exacerbate the } \\
\text { shortage in the healthcare setting. }\end{array}$ & $\begin{array}{l}\text { - Mandatory mask policies inside } \\
\text { government and private buildings } \\
\text { - Promote revolution artists to produce } \\
\text { mask designs that reflect the values of } \\
\text { the revolution }\end{array}$ \\
\hline Hand hygiene & $\begin{array}{l}\text { - Transmission of virus can occur when the } \\
\text { contaminated hand touches mucous membranes } \\
\text { such as the nose, mouth, or eyes. } \\
\text { - Hand hygiene is an effective infection control } \\
\text { measure for other diseases. }\end{array}$ & $\begin{array}{l}\text { - Hand sanitizers are not widely } \\
\text { accessible. Access to clean water } \\
\text { is limited in several parts of the } \\
\text { country. }\end{array}$ & $\begin{array}{l}\text { - Implement hand-washing stations in } \\
\text { crowded venues } \\
\text { - Expand local production of hand } \\
\text { sanitizers } \\
\text { - Emphasize hand hygiene in early } \\
\text { childhood education }\end{array}$ \\
\hline Testing & $\begin{array}{l}\text { - Nucleic acid amplification test (NAAT) or PCR } \\
\text { testing is the mainstay of diagnosing active } \\
\text { COVID-19 cases. } \\
\text { - Serological essays may be helpful in identifying } \\
\text { prevalence of disease in the population. } \\
\text { - Rapid diagnostic antigen-based testing (RDT) can } \\
\text { be helpful in early identification of positive cases } \\
\text { in symptomatic patients, however, limited by low } \\
\text { sensitivity. }\end{array}$ & $\begin{array}{l}\text { - Limited governmental lab resources } \\
\text { and capacity } \\
\text { - Free testing of returnees and } \\
\text { travelers is placing pressure on } \\
\text { governmental labs. } \\
\text { - Limited transportation of testing } \\
\text { from states to the national public } \\
\text { health lab } \\
\text { - Inadequate staffing of laboratory } \\
\text { and lack of trained personnel }\end{array}$ & $\begin{array}{l}\text { - Apply testing effectively considering } \\
\text { the limited resources } \\
\text { - Limit testing to symptomatic patients } \\
\text { - Expand testing locations } \\
\text { - Implement online testing portals in } \\
\text { major cities } \\
\text { - Develop an algorithm for implementing } \\
\text { RDT antigen-based testing in remote } \\
\text { areas and refugee camps } \\
\text { - Utilize serologic testing for prevalence } \\
\text { studies in asymptomatic patients }\end{array}$ \\
\hline $\begin{array}{l}\text { Isolation and } \\
\text { quarantine }\end{array}$ & $\begin{array}{l}\text { - Home isolation is indicated for symptomatic } \\
\text { healthy adults who have high suspicion of } \\
\text { COVID without testing, and test-confirmed } \\
\text { COVID cases. } \\
\text { - Home isolation is sufficient for } 80 \% \text { of cases. } \\
\text { - Hospitalization is needed for } 10-15 \% \text { of } \\
\text { COVID-19 patients. } \\
\text { - Live virus was not detected after } 9 \text { days from } \\
\text { symptoms onset; therefore, isolation for } 10 \text { days } \\
\text { is sufficient for most cases. } \\
\text { - Incubation period of COVID-19 can be up to } 14 \\
\text { days; therefore, exposed contacts should } \\
\text { quarantine for } 14 \text { days. }\end{array}$ & $\begin{array}{l}\text { - Financial challenges facing } \\
\text { households under isolation and } \\
\text { quarantine } \\
\text { - Large household sizes } \\
\text { - Limited isolation centers at public } \\
\text { hospitals } \\
\text { - Isolation center staffed mostly by } \\
\text { volunteers }\end{array}$ & $\begin{array}{l}\text { - Provide financial support for families } \\
\text { under isolation and quarantine } \\
\text { - Temporary employment of community } \\
\text { volunteers to assist in education and } \\
\text { home delivery of groceries and } \\
\text { supplies } \\
\text { - Establish isolation floors in major } \\
\text { public hospitals } \\
\text { - Incentivize staff working in isolation } \\
\text { hospitals } \\
\text { - Establish residential isolation centers } \\
\text { for those who are unable to quarantine } \\
\text { or isolate at home }\end{array}$ \\
\hline Contact tracing & $\begin{array}{l}\text { - Contact tracing and quarantine of exposed close } \\
\text { contacts can interrupt the transmission chain of } \\
\text { COVID- } 19 \text {. } \\
\text { - All contacts of confirmed COVID-19 cases should } \\
\text { be identified and traced. }\end{array}$ & $\begin{array}{l}\text { - Lack of public health infrastructure } \\
\text { - Limited number of trained } \\
\text { personnel } \\
\text { - Stigma related to the disease } \\
\text { - Limited access to technology in } \\
\text { remote and rural areas }\end{array}$ & $\begin{array}{l}\text { - Leverage resistance and service } \\
\text { committees to assist the } \\
\text { contact-tracing team } \\
\text { - Remote program using online portals } \\
\text { and telemedicine } \\
\text { - Explore use of cellphone data in contact } \\
\text { tracing } \\
\text { - Destigmization campaign led by } \\
\text { celebrities and artists }\end{array}$ \\
\hline
\end{tabular}

implementing these measures in Sudan, it is important to refrain from a one-size-fits-all implementation strategy as health control measures will have to conform to local culture and tradition in order for them to be adopted.

\section{Conclusions}

Sudan, like most countries faced the challenges of combating COVID-19. The country was emerging from 30 years of a dictatorship that underfunded the healthcare system and drove most qualified health professionals out of the country. Luckily, the pandemic occurred after the fall of the dictatorship and formation of the transitional government, which took the pandemic seriously and instituted evidence-based measures to confront it. Furthermore, the Sudanese diaspora came to the aid of the country by providing money, supplies as well as mobilizing the community to respond to COVID-19. However, political, religious 
and cultural factors negatively impacted the efforts to combat the pandemic.

\section{Declarations}

Conflict of Interest The authors declare no competing interests.

Human and Animal Rights and Informed Consent This article does not contain any studies with human or animal subjects performed by any of the authors.

\section{References}

1. Sudan F. Sudan Health Observatory 2020; http://www.sho.gov.sd/ controller/.

2. Worldometers. Sudan coronavirus cases. In:2020. https://www. worldometers.info/coronavirus/country/sudan/.

3. Pearson CA, Van Schalkwyk C, Foss AM, et al. Projected early spread of COVID-19 in Africa through 1 June 2020. Euro Surveill. 2020;25(18)

4. Carl A.B. Pearson* KvZ, Christopher I Jarvis, Nicholas Davies, Francesco Checchi, CMMID nCov working group, Mark Jit \& Rosalind M Eggo*. Projections of COVID-19 epidemics in LMIC countries. 05-06-2020 2020.

5. House W. Opening up America again. 2020. https://www. whitehouse.gov/openingamerica/.

6. Ahmed Mushfiq Mobarak ZB-H. Poor countries need to think twice about social distancing. Foreign Policy2020. https:// foreignpolicy.com/2020/04/10/poor-countries-social-distancingcoronavirus/.

7. Zachary Barnett-Howell AMM. Should low-income countries impose the same social distancing guidelines as Europe and North America to halt the spread of COVID-19? . Yale School of Management. 2020.

8. IMF. Sudan interim poverty reduction strategy paper. 2013. https:// www.imf.org/en/Publications/CR/Issues/2016/12/31/SudanInterim-Poverty-Reduction-Strategy-Paper-41025.

9. Reports C. Traffic and road conditions in Sudan. 2019. https:// www.osac.gov/Content/Report/b81d59a2-d243-4e7f-87cb$15 f 4 a e a e 564 \mathrm{e}$

10. Index GH. Global Hunger Index: Sudan. 2019. https://www. globalhungerindex.org/pdf/en/2019/Sudan.pdf.

11. WHO. Humanitarian needs overview sudan. World Health Organization;2020. Available at https://reliefweb.int/sites/ reliefweb.int/files/resources/Sudan_2020_HNO.pdf.

12. Reports N. Sudan could spend up to $70 \%$ of its budget on several war fronts this year. Quartz Africa2016. Available at https://qz. com/africa/615938/sudan-could-spend-up-to-70-of-its-budget-onseveral-war-fronts-this-year/.

13. Global Health Observatory. Current health expenditure (CHE). World Health Organization;2020. https://www.who.int/data/gho/ data/themes/topics/indicator-groups/indicator-group-details/GHO/ current-health-expenditure-(che).

14. Global Health Observatory. Sudan statistics summary (2002 present). 2020. Available at https://apps.who.int/gho/data/node. country.country-SDN.

15. Bein MA, Unlucan D, Olowu G, Kalifa W. Healthcare spending and health outcomes: evidence from selected East African countries. Afr Health Sci. 2017;17(1):247-54.
16. Noory B, Hassanain SA, Lindskog BV, Elsony A, Bjune GA. Exploring the consequences of decentralization: has privatization of health services been the perceived effect of decentralization in Khartoum locality, Sudan? BMC Health Serv Res. 2020;20(1):669.

17. Ebrahim EM, Ghebrehiwot L, Abdalgfar T, Juni MH. health care system in Sudan: review and analysis of strength, weakness, opportunity, and threats (SWOT analysis). Sudan Journal of Medical Sciences. 2017;12(3).

18. Bezuidenhout L, Karrar O, Lezaun J, Nobes A. Economic sanctions and academia: overlooked impact and long-term consequences. PLoS One. 2019;14(10):e0222669.

19. Abdalla FM, Omar MA, Badr EE. Contribution of Sudanese medical diaspora to the healthcare delivery system in Sudan: exploring options and barriers. Hum Resour Health. 2016;14(Suppl 1):28.

20. Organization WH. Eastern Mediterranean Region Framework for health information systems and core indicators for monitoring health situation and health system performance. 2016.

21. Sudan Federal Ministry of Health. National human resources for health strategic plan for Sudan, 2012-2016. 2011. Available at https://www.who.int/workforcealliance/countries/Sudan HRHPlan_2012-16.pdf?ua=1.

22. Ro C. Why health workers in Sudan have been leaving their post amist COVID-19. In. Forbes2020. https://www.forbes.com/sites/ christinero/2020/06/25/why-health-workers-in-sudan-have-beenleaving-their-posts-amid-covid-19/\#668e5aa753ac.

23. Worldometers. Sudan population. 2020. https://www. worldometers.info/world-population/sudan-population/.

24. Schneider EC. Failing the test - the tragic data gap undermining the U.S. pandemic response. New England Journal of Medicine. 2020;383(4):299-302.

25. IMF. Vietnam's success in containing COVID-19 offers roadmap for other developing countries. 2020. Available at https://www.imf. org/en/News/Articles/2020/06/29/na062920-vietnams-success-incontaining-covid19-offers-roadmap-for-other-developingcountries.

26. Sahal N, Reintjes R, Mahgoub AE, Aro AR. Staff views about the quality of the Communicable Diseases Surveillance System in Khartoum State, Sudan, 2005-2007: a qualitative study. East Mediterr Health J. 2011;17(7):565-9.

27. Sahal N, Reintjes R, Eltayeb EM, Aro AR. Assessment of core activities and supportive functions for the communicable diseases surveillance system in Khartoum state, Sudan, 2005-2007. East Mediterr Health J. 2012;16(12):1204-10.

28. DHIS. DHIS2 In Action. 2020; https://www.dhis2.org/inaction.

29. Wilkinson A, Parker M, Martineau F, Leach M. Engaging 'communities': anthropological insights from the West African Ebola epidemic. Philos Trans R Soc Lond B Biol Sci. 2017;372(1721). https://doi.org/10.1098/rstb.2016.0305.

30. Organization WH. Community engagement and social mobilization; https://www.who.int/csr/disease/ebola/training/communityengagement/en/.

31. Sudan U. COVID-19 \& Stigma: What you need to know. 2020; https://www.unicef.org/sudan/stories/covid-19-stigma-what-youneed-know.

32. Frehywot $\mathrm{S}$, Park $\mathrm{C}$, Infanzon A. Medical diaspora: an underused entity in low- and middle-income countries' health system development. Hum Resour Health. 2019;17(1):56.

33. Epidemics P. Box-It-In. 2020; https://preventepidemics.org/ covid19/science/insights/box-it-in/.

Publisher's Note Springer Nature remains neutral with regard to jurisdictional claims in published maps and institutional affiliations. 